\title{
Analysis of the suction evolution during direct shear test in a silty sand soil
}

\author{
Omar AL-Emami ${ }^{1, *}$, Gabriela M. Medero ${ }^{1}$, Fernando A. M. Marinho ${ }^{2}$, and Melis Sutman ${ }^{1}$ \\ ${ }^{1}$ EGIS School, Heriot-Watt University, United Kingdom \\ ${ }^{2}$ University of São Paulo, Brazil
}

\begin{abstract}
Shear strength of soils is one of the essential parameters for analysing and solving divers geotechnical problems (e.g. the bearing capacity of shallow footings pile foundations, slope stability and earth embankments). In this study, a series of conventional large-scale (300 X $300 \mathrm{~mm})$ direct shear tests were carried out on saturated and constant water content silty sand specimens at ei $=0.6$ and 1.0 tested under applied vertical stresses of 100,200 , or $400 \mathrm{kPa}$ to investigate the influence of matric suction on the shear strength characteristics of the tested material. A loading steel cap was modified to allow the direct measurements of the matric suction using two commercial available Equitensiometer suction probes (EQ3). The experimental program indicated that, for both studied void ratios, the obtained shear strength of specimens under constant water content is found to be distinctly greater than those obtained from saturated samples. The results showed that the samples compacted at ei $=1.0$ exhibited collapse behaviour during saturation stage, whereas same samples did not show any volume change during stabilisation stage when tested under constant water content condition. The study results also showed that the matric suction reduction during consolidation stage depends on initial void ratio of the tested samples as well as the level of applied vertical stress. Moreover, the matric suction evolution during shearing process of both studied void ratios specimens decreased with increasing the level of applied vertical stress.
\end{abstract}

\section{Introduction}

In nature, the soil located in the zone between the deepest water table and the earth's surface is usually defined as the unsaturated soil. Unsaturated soil is generally defined as a three-phase system composed of soil solids, water, and air. The relative distribution of these three components is important to understand the properties of the soil, primarily because the nature of the air - water interface is controlled by the distribution of these three components. Fredlund and Morgenstern [1] introduced a fourth phase called the contractile skin, which is the same as the water-air interface. The water-air interface affects volume change and shear strength [2].

In engineering practice, soil compaction is the mechanical process producing unsaturated soils which generally contain a combination of water and air in their voids between the soil particles and have a degree of saturation ranging from $75-90 \%$ [3]. Several man-made geotechnical infrastructures such as earth dams, roads, embankments and retaining walls are actual examples involved in their construction on the use of the compacted soils. Soil suction is one of the most important parameters widely used to depict the soil moisture stress status in the unsaturated soils. The performance of the geotechnical infrastructures is highly influenced by the matric suction changes along with volumetric strains emerging under

\footnotetext{
Corresponding author: oha31@hw.ac.uk
}

constant water content condition. Matric suction development in an unsaturated soil under constant water content condition is an important factor in determining and interpreting both shear strength and volume change behaviour [4]. Triaxial and direct shear tests are vastly used for determining the shear strength and volume change behaviour of soils. The data obtained from these tests are usually used in the design and safety assessment of many civil engineering projects.

During the last two decades, a few researchers $[4,5,6$, 7 and 8] have performed a series of suction-controlled triaxial tests to study the significant influences of different factors (e.g. water content, initial soil suction, soil density, degree of saturation and different levels of vertical stress) on the mechanical and hydraulic behaviours of compacted soil specimens under constant water content condition. The researchers examined the effect of these factors on relationships between matric suction development and the corresponding changes in the shear strength and volume behaviour under constant water content condition. Chu and Mou [9] studied the effect of the compaction method, the water content and the soil density on the soil suction development for an expansive clayey soil. Their results revealed that the soil suction of the tested samples at the same compacting water content increased as the density of soil increased. $\mathrm{Ng}$ and Pang [10] indicated that the samples tested under 
higher net normal stress have larger matric suction in comparison to those tested under lower net normal stress. In contrast, different trends of behaviour were observed by $[11,12]$. The authors pointed out that, at the same initial water content, the matric suction development of a residual soil of gneiss was higher when the tested samples were compacted with low energy than with high compaction energy. The test results indicated by Tripathy et al., [13] showed that the soil suction of soil specimens decreased with increasing soil density at the same molding water content. Oliveria et al. [4] showed that the matric suction changes of compacted fine-grained soils under constant water content depend on the volume change behaviour which is significantly influenced by the level of confining pressure, the degree of saturation and the soil structure. Their results suggest that the degree of saturation increases and matric suction decreases when the soil samples contract.

From the above previous studies, it is clear to see that the level of applied stress and the initial soil density had a significant influence on the soil suction development. However, the degree of influence appears to be uncertain and need further investigation. In the present study, a silty sand soil was used to evaluate the effect of two void ratios (i.e. two different densities) and three levels of applied vertical stress on the shear strength and volume change behaviour of the tested samples.

\section{Methodology and studied soil}

\subsection{Soil material}

The artificial soil was created using sand obtained from Geotechnical laboratory of the Institute of Infrastructure \& Environment, Heriot-Watt University, United Kingdom and kaolin clay (supplied by Whitfield \& Son Ltd., England). The characterisation properties of the artificially prepared soil were determined following the British Standard [14]. These tests are the particle size distribution (dry sieving), the Atterberg limits including the liquid limit and the plastic limit, and the specific gravity of the soil solids. The standard compaction test was performed following the procedure in the British standard [15]. The minimum and maximum index density tests were carried out by using American Society for Testing and Materials [16, 17], respectively. Furthermore, the sand percentage in the prepared soil contains $2 \%$, $54 \%$ and $25 \%$ of coarse, medium and fine sand of particle size between $0.6-2 \mathrm{~mm}, 0.6-0.2 \mathrm{~mm}$, and 0.06-0.2 $\mathrm{mm}$ respectively. The average diameter of the tested soil $\left(D_{50}\right)$ is $0.2 \mathrm{~mm}$. The main properties of the prepared soil are presented in Table 1.

\subsection{Sample preparation and testing procedures}

Prior to compaction, the dried soil (24 hours in $105^{\circ} \mathrm{C}$ ) was mixed with an appropriate amount of distilled water to achieve a target moisture content $(\omega=8 \pm 1 \%)$ and then, the mixture was stored inside well sealed plastic bags and allowed to reach equilibrium for 3 days. After that, the soil was directly compacted inside the shear box into four layers (35mm thickness each) by dynamic compaction.

Table 1. Main properties of the prepared soil.

\begin{tabular}{|l|c|}
\hline \multicolumn{1}{|c|}{ Soil property } & Prepared soil \\
\hline Specific gravity of soil solids, $G_{s}$ & 2.66 \\
\hline Sand (\%) & 81 \\
\hline Silt (\%) & 17 \\
\hline Clay (\%) & 2 \\
\hline Coefficient of uniformity, $\mathrm{C}_{\mathrm{u}}$ & 6.81 \\
\hline Coefficient of curvature, $\mathrm{C}_{\mathrm{c}}$ & 5.12 \\
\hline Liquid Limit, $L L(\%)$ & 9.50 \\
\hline Plastic Limit, $P L(\%)$ & 7.10 \\
\hline Plasticity Index, PI & 2.4 \\
\hline Maximum void ratio, $e_{\max }$ & 0.985 \\
\hline Minimum void ratio, $e_{\min }$ & 0.354 \\
\hline Maximum dry density, $\rho_{d \max }\left(\mathrm{gm} / \mathrm{cm}^{3}\right)$ & 1.922 \\
\hline Optimum moisture content, $(\%)$ & 9.5 \\
\hline Soil Unified Classification $S y s t e m$ & $\mathrm{SM}$ \\
\hline
\end{tabular}

\subsubsection{Direct shear tests at saturated state}

After completing the compaction, the soil specimen was first soaked by water in the direct shear carriage. The soil specimen in the direct shear cell was allowed to soak water for 24 hours under a nominal surcharge load (steel cap). The height of the specimen before and after saturation was monitored to indicate any change in the specimen height at the end of saturation stage.

Once reaching the saturation (i.e. after 24 hours), consolidation at constant vertical load was undertaken. Consolidation of the specimen was noticed to be achieved when no further increase in the vertical displacement was observed (approximately steady state). Following, the soil specimen was sheared under constant vertical load and constant rate of horizontal displacement $(0.05 \mathrm{~mm} / \mathrm{min})$. This rate was in agreement with those reported by [18] for similar material.

\subsubsection{Direct shear tests at constant water content state}

The experimental programme was carried out using a Wykeham Farrance Engineering Ltd., Model WF 40200, Shear Box Machine. The machine is equipped with two Linear Variable Different Transformers (LVDTs) which were used for measuring the horizontal and vertical displacements. One load cell having capacity of $100 \mathrm{kN}$ is installed for measuring the horizontal shear force. The test procedure consists of three stages: soil suction stabilisation, consolidation under predetermined vertical load and shearing at a constant vertical load and constant rate of shear displacement. During suction stabilisation stage, the specimen was allowed to achieve soil suction equilibrium. Equilibration of the specimen was noticed to be achieved when the measured suction was approximately constant $(\leq 1 \%$ changes of the recorded suction) as shown in Figure 1. The stabilisation/equalisation of the suction was analysed based on the data obtained from this figure. Nine days of matric suction stabilisation were found to be satisfactory 
for all tested specimens. It is noteworthy to mention that the suction stabilisation stage was performed under nominal surcharge load (i.e. weight of loading pad only), and the values of stress level are used in Figure 1 to differentiate the plots.

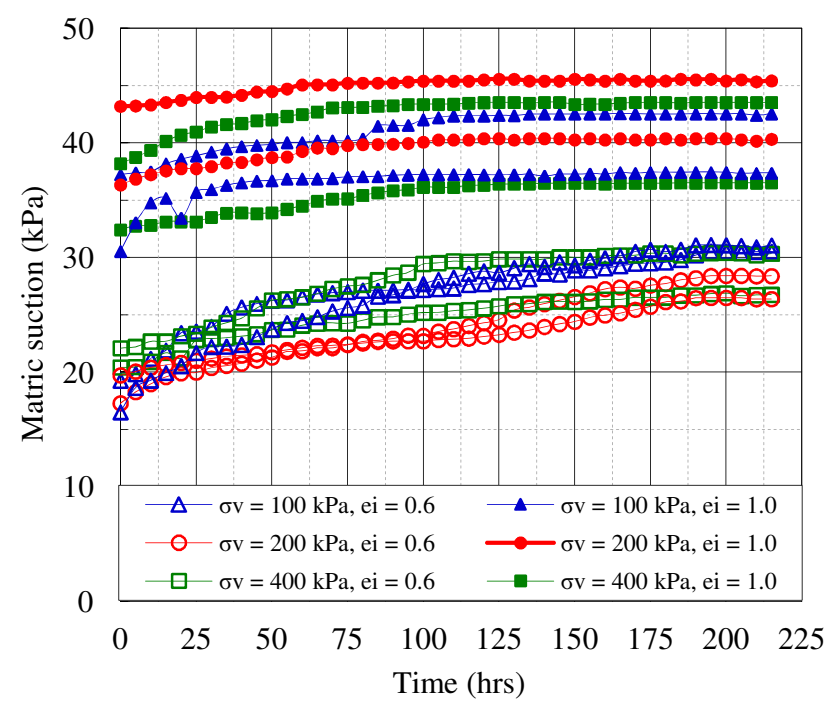

Fig. 1. Matric suction versus time during stabilisation stage for both studied void ratios $\left(e_{i}=0.6\right.$ and 1.0$)$.

After achieving equilibrium, the specimen was allowed to consolidate under the pre-decided vertical load and this represents the second stage of test. Consolidation of the specimen was noticed to be achieved when no further increase in the vertical displacement was observed. Ten hours of consolidation was found to be satisfactory for all tested specimens. The specimen was left an additional two hours to assure that there is no further increase in the vertical displacement. After consolidation, the specimen was subjected to the shearing force at constant vertical load and rate of shear displacement $(0.01 \mathrm{~mm} / \mathrm{min})$.

\subsection{Modifications of conventional direct shear apparatus for constant water content tests}

\subsubsection{Anti-evaporation system}

The main obstacle to perform direct shear test at a constant water content condition is to prevent the evaporation of water from the soil specimen during the testing stages. To do so, the gaps between the lower half of the shear box and the base of carriage were sealed with the waterproof silicon sealant. The surfaces of contact between the two halves of shear box were filled with a thick layer of grease. A plenty of grease was smeared on the external boundary of the contact surface between two halves to prevent any evaporation of water during the testing process. In addition, the space between the upper part of shear box and the loading steel cap was first filled with a light layer of grease then was covered by the jacket of latex membrane, which was sealed to the edges of the loading cap and the upper half of shear box using super glue. It should be noted that the length of latex membrane is adequate for free movement of loading cap during consolidation and shearing stages. It should also be noted that there was no porous material in contact with the specimen due to the specific layout of the apparatus.

\subsubsection{Modification of the steel loading pad}

In order to measure the evolution of soil suction during direct shear test stages, a new loading steel cap of largescale direct shear apparatus for testing soil specimens has been manufactured. The new loading cap was manufactured and set in the Mechanical workshop at Heriot-Watt University. The loading cap having a thickness of $20 \mathrm{~mm}$ and an external dimension of $297 \mathrm{X}$ $297 \mathrm{~mm}$ is consistent with conventional one used for saturated soil testing. The bottom face of the loading cap has seventeen machined symmetrical longitudinal grooves having a dimension of $10 \mathrm{~mm}$ by $297 \mathrm{~mm}$, and a thickness of $4 \mathrm{~mm}$. The design of the grooves in such way provides a good contact between the loading cap and the compacted soil specimen during test process.

Four holes were machined opposite each other in the loading steel cap so that the suction probes can be inserted easily. Each hole has a diameter of $42 \mathrm{~mm}$, which is slightly greater than the diameter of the suction probe. In this study, only two holes were used during all experimental tests while the other two holes were sealed tightly. The two holes were selected through which one suction probe was inserted at the front of the specimen and the other at the rear. The location of the holes was permitted to investigate any suction changes along the length of the soil specimen during the testing stages. During design process, an open-end steel tube having an internal diameter of $42 \mathrm{~mm}$, wall thickness of $3 \mathrm{~mm}$, and a height of $65 \mathrm{~mm}$ was welded diametrically above each hole in order to provide the necessary housing for the suction probe (see Figure 2).

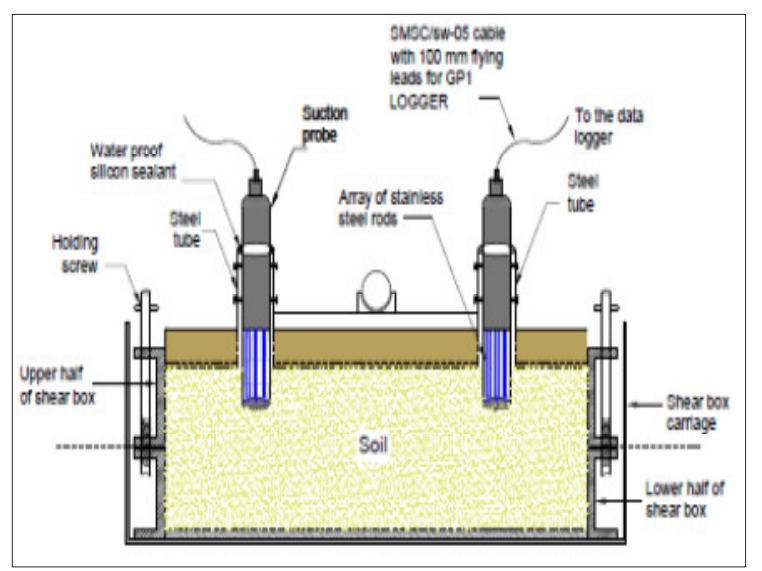

Fig. 2. Schematic drawing of modified shear cell used for soil tests at constant water content condition (not to scale).

To avoid the movement of the suction probe during consolidation and shearing stages, each steel tube was provided with sixth holes at different levels of the steel tube to fix the suction probe by screws. Several pilot tests had been carried out to select the appropriate length of suction probe that will be inserted inside the soil specimen to avoid the possible interference during 
consolidation and shearing stages. Due to cap rotation during shearing stage, it was necessary to check that the front and the back suction probes do not disturb the soil surround them during shearing process. Subsequent direct shear tests revealed that the introduced length of the suction probe did not affect the specimen during shearing.

\section{Analysis and discussion of results}

Table 2 shows the initial and final conditions of the tested specimens during saturation stage. Unlike the dense specimens $\left(\mathrm{e}_{\mathrm{i}}=0.6\right)$, the loose specimens $\left(\mathrm{e}_{\mathrm{i}}=1.0\right)$ exhibited collapse behaviour during saturation stage under nominal surcharge load (i.e. steel pad, equivalent vertical stress of $1.33 \mathrm{kPa}$ ). Based on these observations, it can be concluded that the soil presents collapse behaviour under very low level of applied vertical stress when at low density around $13.3 \mathrm{kN} / \mathrm{m}^{3}\left(\mathrm{e}_{\mathrm{i}}=1.0\right)$.

According to ASTM D 5333 - 92 [19], the observed collapse potential of the tested soil can be classified as moderate to severe. In contrast, same samples $\left(\mathrm{e}_{\mathrm{i}}=1.0\right)$ did not show any volume change during soil suction stabilisation stage when tested under constant water content condition. This behaviour is due to the fact that, for samples at constant water content, the normal force is induced by the capillary tension of water meniscus clinging to the contact point of the soil particles which acts so as to connect the soil particles tightly and hence increases the stiffness of tested samples [20]. The values of stress level are used in Table 2 to differentiate the tests.

Table 2. Void ratio before $\left(\mathrm{e}_{\mathrm{i}}\right)$ and after $\left(\mathrm{e}_{\mathrm{f}}\right)$ saturation stage and calculated collapse potential $(\mathrm{CP})$.

\begin{tabular}{|c|c|c|c|c|c|c|}
\hline \multirow{3}{*}{$\begin{array}{c}\sigma_{\mathrm{v}} \\
(\mathrm{kPa})\end{array}$} & \multicolumn{6}{|c|}{ Target void ratio } \\
\hline & \multicolumn{3}{|c|}{0.6} & \multicolumn{3}{|c|}{1.0} \\
\hline & $e_{i}$ & $e_{f}$ & $\begin{array}{l}\mathrm{CP}, \\
(\%)\end{array}$ & $\mathrm{e}_{\mathrm{i}}$ & $e_{f}$ & $\begin{array}{l}\mathrm{CP}, \\
(\%)\end{array}$ \\
\hline \multirow{2}{*}{100} & 0.597 & 0.597 & \multirow{6}{*}{0} & 1.000 & 0.869 & 6.55 \\
\hline & 0.595 & 0.595 & & 0.996 & 0.873 & 6.13 \\
\hline \multirow{2}{*}{200} & 0.600 & 0.600 & & 0.997 & 0.840 & 7.85 \\
\hline & 0.600 & 0.600 & & 1.000 & 0.857 & 7.15 \\
\hline \multirow{2}{*}{400} & 0.596 & 0.596 & & 0.995 & 0.871 & 6.20 \\
\hline & 0.598 & 0.598 & & 0.998 & 0.859 & 6.92 \\
\hline
\end{tabular}

Figures 3(a) and 3(b) present the relationship between reduction in matric suction associated with loading with respect to time during consolidation stage of samples having $\mathrm{e}_{\mathrm{i}}=0.6$ and 1.0 and tested under constant water content condition, respectively. It can be noticed that for both void ratios, the matric suction reduction of the tested samples increases with the progress of applied vertical stress. The higher is the applied vertical stress, the greater the reductions in matric suction. Looser samples $\left(e_{i}=1.0\right)$ exhibited higher change in matric suctions as compared to the denser samples $\left(e_{i}=0.6\right)$. The larger is the volume contraction, the larger would be the matric suctions reduction in a compacted sample. This trend of behaviour was observed for all levels of vertical stress used in this study. Typical plots for effect of test conditions (saturated
, SAT and constant water content, CON) on the shear strength and volumetric behaviour of the studied materials at $e_{i}=0.6$ and 1.0 are shown in Figures 4 and 5.
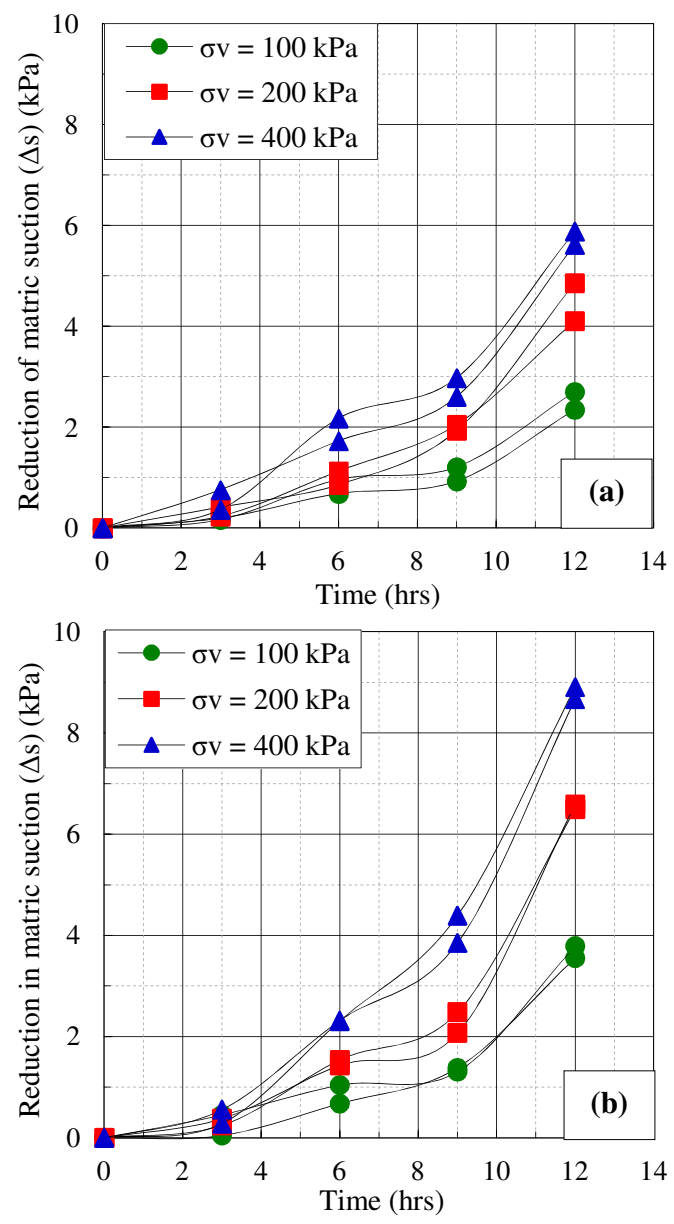

Fig. 3. Reduction in matric suction vs. time during consolidation stage of soil samples at (a) $\mathrm{e}_{\mathrm{i}}=0.6 ;$ (b) $\mathrm{e}_{\mathrm{i}}=1.0$.

From the observation of Figures 4(a) and 5(a), for both studied void ratios, the obtained shear strength of specimens under constant water content are found to be distinctly greater than those obtained from saturated samples. This illustrates the significant role of soil suction on the shear strength behaviour of the tested material, as expected and vastly shown in the literature [e.g. 21, 22]. This behaviour can be attributed to the fact that, in saturated soil, the pore spaces are filled with water that potentially can acts as lubricant agent between particles, and hence reduce the shear strength [23, 24]. As opposed to the saturated samples, at constant water content the matric suction generated due to menisci of water formation increase the shear strength and stiffness of the tested specimens [25].

The test results presented in Figure 4(a) for initial void ratio of 0.6 reveal that the horizontal displacement corresponding to the peak/maximum shear strength varies differently even between the duplicate tests. For both test conditions, the horizontal displacement corresponding to peak/maximum shear strength tends to increase with increasing the level of applied vertical stress. 

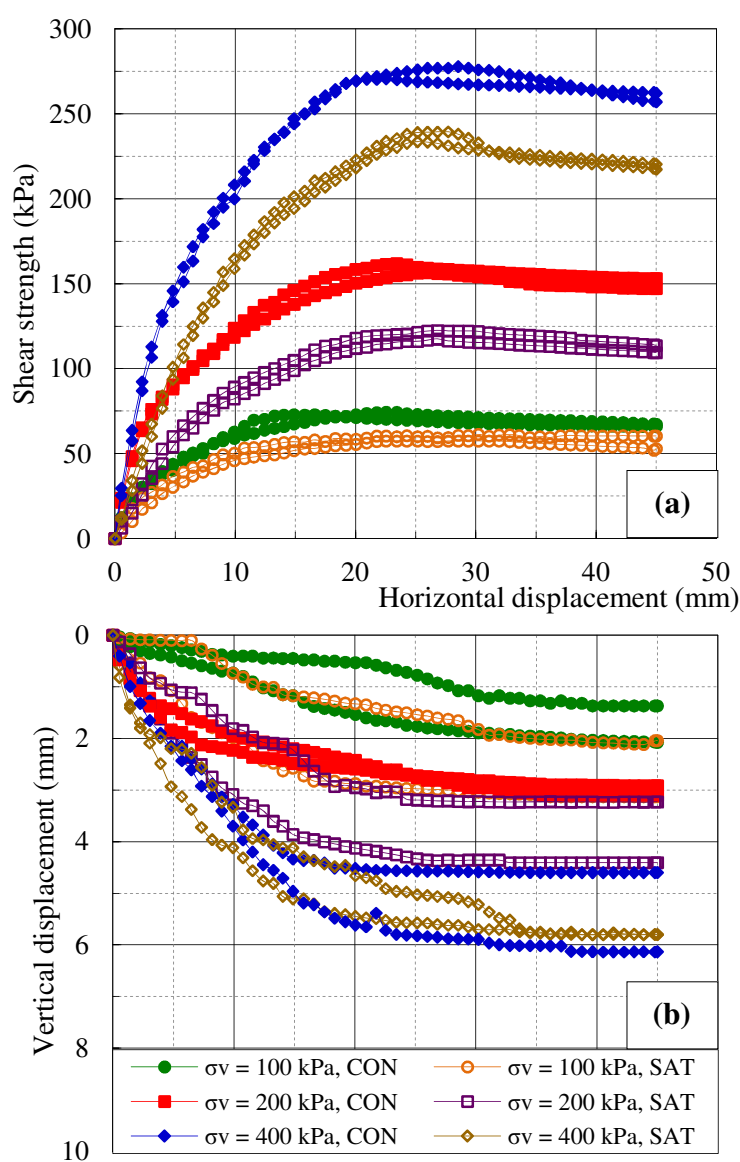

Fig. 4. Direct shear results of silty sand samples for $e_{i}=0.6$ : effect of test condition on (a) shear strength; (b) volumetric behaviour

No clear correlation (Figure 5(a) for initial void ratio 1.0) was found between the horizontal displacements corresponding to the maximum/peak shear strength. In Figure 4(a), denser specimens $\left(e_{i}=0.6\right)$ tested under saturated and constant water content conditions exhibited strain softening behaviour (peak shear strength pattern). In contrast, looser specimens $\left(e_{i}=1.0\right)$ showed clear hardening behaviour after reaching the maximum shear strength for all tested samples (non-peak shear strength pattern) except samples sheared under $400 \mathrm{kPa}$ applied vertical stress as shown in Figure 5(a).

By considering the results presented in Figures 4(a) and 5(a), it can be concluded that the role of the matric suction in the post peak shear strength region is less significant in the sense that the shear strength curves exhibited different patterns of behaviour (i.e. strain softening or strain hardening behaviour). This trend of behaviour has been observed by many researchers [21, 26, 27]. It can also be noticed from Figures 3(b) and 4(b), for the range of applied vertical stresses, the constant water content specimens have shown lower value of vertical displacement in comparison with the corresponding saturated one.

In order to analyse the matric suction evolution during shearing, the matric suction has been corrected to zero at the beginning of shearing stage. Test results of samples $\left(e_{i}=0.6\right.$ and 1.0) are presented in Figure 6. In general, it can be noticed that the matric suction during shearing process of specimens studied at both void ratios decreases with increasing the level of applied vertical stress.
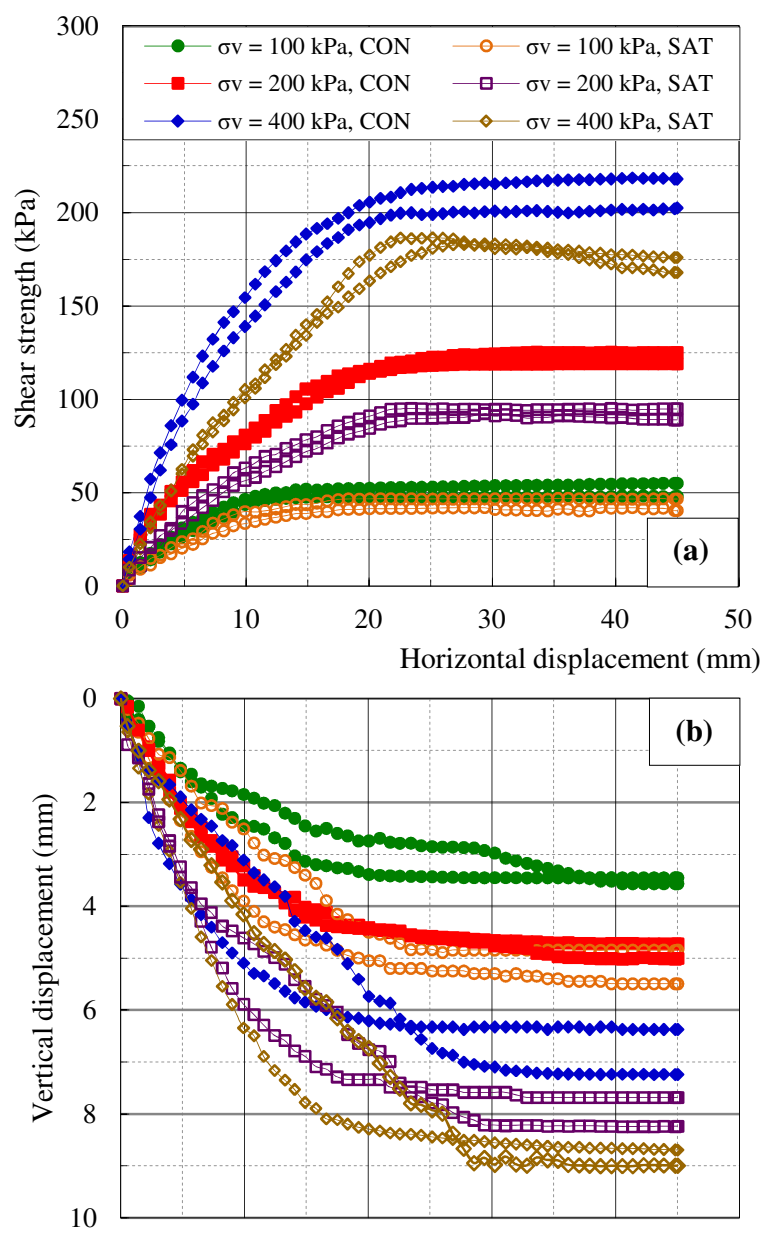

Fig. 5. Direct shear results of silty sand samples for $e_{i}=1.0$ : effect of test condition on (a) shear strength; (b) volumetric behaviour.

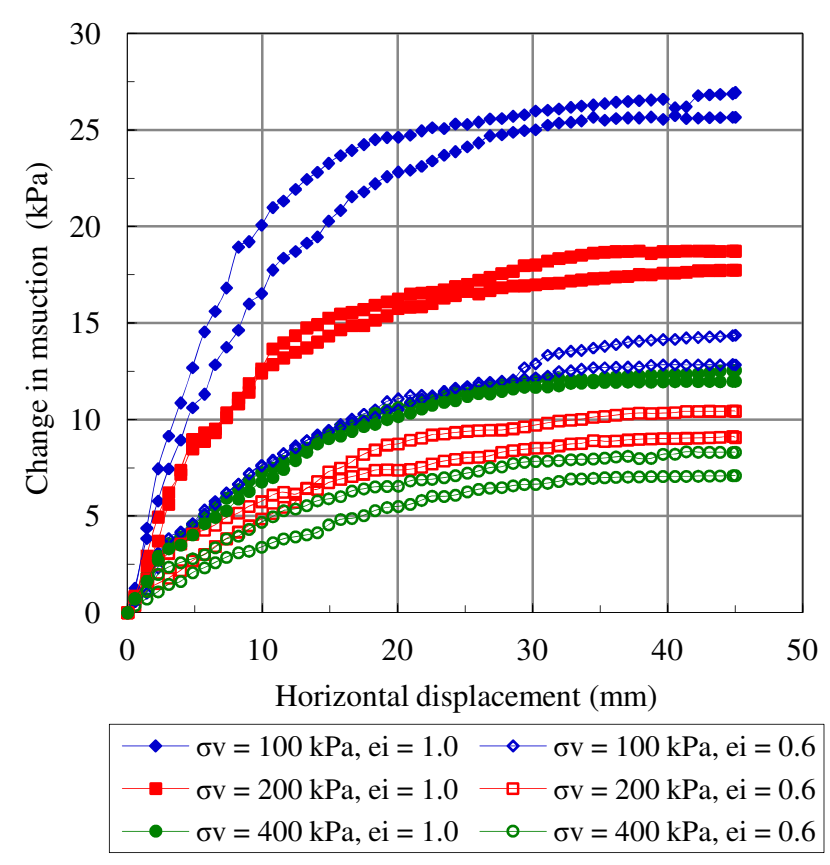

Fig. 6. Evolution of matric suction with horizontal displacement during shearing process of soil samples at $e_{i}=0.6$ and 1.0. 
In general, it can be noticed that the matric suction during shearing process of specimens studied at both void ratios decreases with increasing the level of applied vertical stress. The higher the applied vertical stress, the denser the soil specimen, and hence the lower the matric suction is. This trend of behaviour is consistent with what was observed by $[11,12,13]$. Figure 6 also shows that there is a noticeable dependency of matric suction on initial value of void ratio. Samples prepared with high void ratio revealed higher matric suction than those prepared at low void ratio. This trend of behaviour was observed for all levels of vertical stress. Furthermore, as the horizontal displacement increased, the measured matric suction either remained unchanged or increased slightly in the post-peak region.

To define the effective friction angle, $\phi^{\prime}$ and effective cohesion, $\mathrm{c}^{\prime}$ parameters of saturated samples, the peak/maximum shear strength is plotted against the effective normal stress in Figure 7, for $e_{i}=0.6$ and 1.0. Linear shear strength envelopes are considered over the range of the applied vertical stress levels (100 to 400 $\mathrm{kPa}$ ), and best fit lines are drawn. Figure 7 reveals that the increase in void ratio causes a clear decrease in the effective friction angle (see Table 3). Furthermore, for samples tested at constant water content state the general tendency of friction angle, $\phi$ shows an increase with decreasing void ratio as shown in Figure 8 and Table 4. However, at constant water content state the friction angle is greater than those at saturated state. Similar to the saturated shear strength envelopes, the shear strength envelopes for constant water content samples show good linearity over the same range of vertical stress.

Table 3. Shear strength parameters for different values of void ratio samples (saturated state).

\begin{tabular}{|c|c|c|c|c|}
\hline \multirow{2}{*}{$\begin{array}{c}\text { Initial void } \\
\text { ratio, } \mathrm{e}_{\mathrm{i}}\end{array}$} & \multirow{2}{*}{$\begin{array}{c}\text { Test } \\
\text { condition }\end{array}$} & $\phi^{\prime}$ & $\mathrm{c}^{\prime}$ & $\mathrm{R}^{2}$ \\
\cline { 3 - 5 } & & $($ Degree $)$ & $(\mathrm{kPa})$ & \\
\hline \multirow{2}{*}{0.6} & \multirow{3}{*}{ Saturated } & 32.5 & 4 & 0.9998 \\
\cline { 3 - 5 } & & 33 & 2.5 & 0.9999 \\
\cline { 3 - 5 } & & 26.5 & 0 & 0.9984 \\
\cline { 3 - 5 } & & 27 & 0 & 1.0000 \\
\hline
\end{tabular}

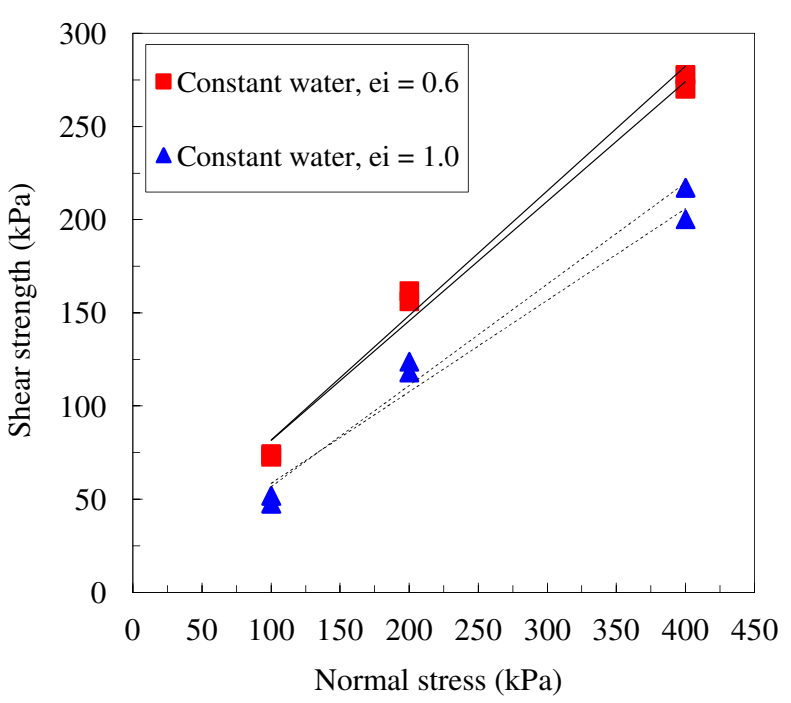

Fig. 7. Mohr-Coulomb failure envelopes of different void ratio samples at saturated state.
The test results presented in Figures 7 and 8 in conjunction with Tables 3 and 4 show that the cohesion of the $e_{i}=0.6$ samples increased by four times when performed at constant water content condition in comparison with the saturated samples, while at $\mathrm{e}_{\mathrm{i}}=1.0$, the cohesion was zero for the saturated condition and ranged between 5 and $9 \mathrm{kPa}$ at constant water content. This shows a coupled influence of saturation state together with the density of the tested samples. At constant water content, there is an apparent increase in the bonding between soil particles due to the negative pressure generating matric suction at the contact points in between particles.

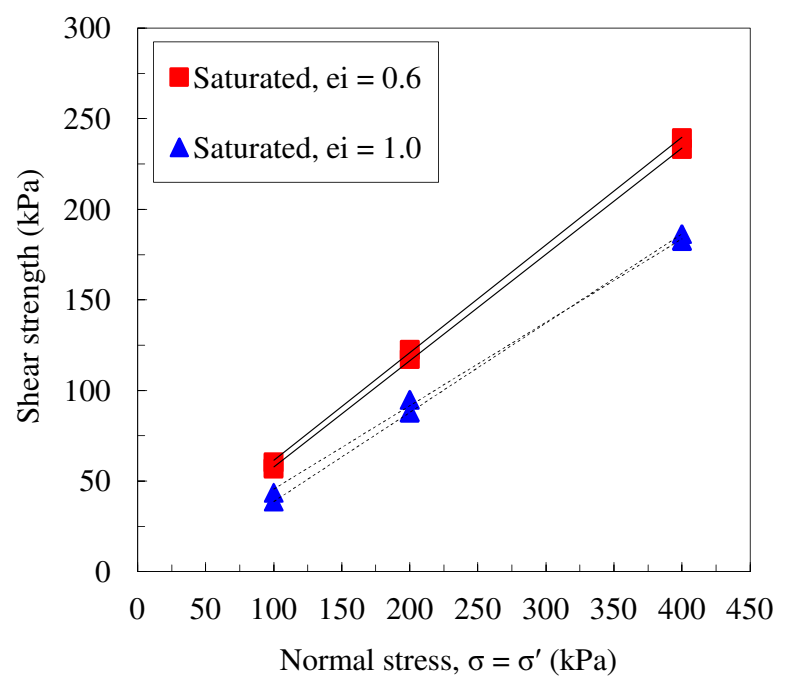

Fig. 8. Mohr-Coulomb failure envelopes of different void ratio samples at constant water content state.

Table 4. Shear strength parameters for different values of void ratio samples (constant water content state)

\begin{tabular}{|c|c|c|c|c|}
\hline \multirow{2}{*}{$\begin{array}{c}\text { Initial void } \\
\text { ratio, } \mathrm{e}_{\mathrm{i}}\end{array}$} & \multirow{2}{*}{$\begin{array}{c}\text { Test } \\
\text { condition }\end{array}$} & $\phi$ & $\mathrm{c}$ & $\mathrm{R}^{2}$ \\
\cline { 3 - 5 } & & $($ Degree $)$ & $(\mathrm{kPa})$ & \\
\hline \multirow{2}{*}{0.6} & \multirow{3}{*}{$\begin{array}{c}\text { Constant } \\
\text { water }\end{array}$} & 36 & 17 & 0.9871 \\
\cline { 3 - 5 } & & 36.5 & 16 & 0.9908 \\
\cline { 3 - 5 } & & 29.5 & 5 & 0.9942 \\
\hline \multirow{2}{*}{1.0} & & 29 & 9 & 0.9647 \\
\hline
\end{tabular}

\section{Conclusions}

In this study, conventional large-scale direct shear apparatus integrated with Equitensiometer suction probes (EQ3) was used to measure the evolution of matric suction in the compacted silty sand soil samples.

The following conclusions are drawn based on the laboratory tests:

1. The test results indicate that level of applied vertical stress and void ratios have a remarkable influence on the shear strength and the corresponding volume change of the tested samples. In addition, for both studied void ratios, the obtained shear strength of specimens under constant water content is found to be distinctly greater than those obtained from saturated samples.

2. The experimental results revealed that the matric suction evolution during consolidation stage depends 
mainly on the volume change behaviour of the compacted samples. The larger is the volume contraction; the greater is the degree of saturation, and hence the greater is the matric suction reduction.

3. The vertical stress level and the value of void ratio of the tested sample have significant effect on the matric suction changes during shearing stage under constant water content condition.

4. From the experimental work, it can be found that there is a tangible tendency that, for both test conditions, the denser samples $\left(\mathrm{e}_{\mathrm{i}}=0.6\right)$ had peak behaviour (strain softening) while looser samples $\left(e_{i}=1.0\right)$ did not show any peak strength behaviour (strain hardening), which indicates the role of the matric suction in the post peak shear strength region being less significant.

5. The failure envelopes with respect to different stress levels show linear behaviour for both saturated and constant water content conditions. It was found that the angle of friction $\phi^{\prime}$ and soil cohesion $c^{\prime}$ experienced noticeable increase as degree of saturation of the tested samples decrease.

\section{References}

1. D.G. Fredlund, N.R. Morgenstern, 1977, J. of Geo. Eng. Div. 103, 447 - 466 (1977)

2. D.G. Fredlund, H. Rahardjo, M.D. Fredlund, Unsaturated soil mechanics in engineering practice, John Wiley \& Sons, (2012)

3. E. Murray, V, Sivakumar, Unsaturated soils a fundamental interpretation of soil behaviour, WileyBlackwell, United Kingdom (2010)

4. O.M.D. Oliveira, P. Li, F.A.M. Marinho, S.K. Vanapalli S. K., Ind. Geo. J. 46, 3, 299 - 308 (2016)

5. C.L. Chen, D.F. Zhang, Y.Z. Dong, H. Chen, D.B. Yu, J.X. Xue, Chin. J. Geo. Eng., 36, 7, 1195 1202 (in Chinese) (2006)

6. A. Jotisankasa, M. Coop, A. Ridley A., Géot., 59, 5, 415 - 428 (2009)

7. T.M. Thu, H. Rahardjo, E.C. Leong, J. Geo. Geoe. Eng., 132, 411 - 419 (2006)

8. S.R. Yang, H.D. Lin, W.H. Huang W. H., J. of Mech., 28, 3, 431 - 437 (2012)

9. T.Y. Chu, C.H. Mou, Transportation Research Board, Washington, D.C., 54 - 60 (1981)

10. C.W.W. Ng, Y.W. Pang, J. Geo. Geoe. Eng., 126, $157-166$ (2000)

11. F.A.M. Marinho, M.M. Stuermer, Geo. Spe. Pub. 99, ASCE, 25-141, (2002)

12. S.M. Rao, K. Revanasiddappa, J. of Geo. and Geoe. Eng., 126, 85 - 90 (2003)

13. S. Tripathy, E.C. Leong, H. Rahardjo, H., From Experimental Evidence Towards Numerical Modeling of Unsaturated Soils, Weimar, Germany, $111-122$ (2003)

14. BS 1377-2, 1990. Soils for civil engineering: Classification tests, British Standards Institution
15. BS 1377-4, 1990. Methods of test for soils for civil: Compaction-related tests, British Standards Institution

16. American Society for Testing and Materials (ASTM), 2000. Standard Test Methods for Minimum Index Density and Unit Weight of Soils and Calculation of Relative Density. Designation ASTM D 4254-00.

17. American Society for Testing and Materials (ASTM), 2000. Standard Test Methods for Maximum Index Density and Unit Weight of Soils Using a Vibratory Table. Designation ASTM D 4253-00.

18. K. Thermann, C. Gau, J. Tiedemann, IAEG, 1-12 (2006)

19. ASTM D5333-92(1996), Standard Test Method for Measurement of Collapse Potential of Soils, ASTM International, West Conshohocken, PA, 1996, www.astm.org

20. D. Karube, K. Kawai K., 2001, Geo. and Geol. Eng., 19, 3, $211-241$ (2001)

21. M.A. Hossain, J.H. Yin J. H., Can. Geo. J., 47, 10, 1112 - $1126(2010)$

22. R.Z. Moayed, M. Alibolandi, A. Alizadeh, Int. J. of Geo. Eng., 11, 2, 1 - 8 (2012)

23. R.F. Craig, Soil mechanics, $5^{\text {th }}$ edn., Chapman and Hall, London, UK (1992)

24. B.M. Das, Fundamentals of geotechnical engineering, CENGAGE Learning, Stamford, CT (2008)

25. S. Wheeler, D. Karube, Proceedings of the first international conference on unsaturated soils, Paris, 1323-1350 (1995)

26. T.B. Hamid, Ph.D. thesis, University of Oklahoma, Oklahoma, United States (2005)

27. L. Borana, J. Yin, D. Singh, S. Shukla S., Mar. and Geor. and Geo., 33, 289 - 298 (2013) 